\title{
The CpG island methylator phenotype may confer a survival benefit in patients with stage II or III colorectal carcinomas receiving fluoropyrimidine-based adjuvant chemotherapy
}

\author{
Byung-Hoon Min ${ }^{1}$, Jeong Mo Bae², Eui Jin Lee ${ }^{3}$, Hong Suk Yu', Young-Ho Kim', Dong Kyung Chang ${ }^{1}$,
} Hee Cheol Kim ${ }^{4}$, Cheol Keun Park ${ }^{3}$, Suk-Hee Lee ${ }^{5}$ Kyoung-Mee Kim ${ }^{3^{*}}$ and Gyeong Hoon Kang ${ }^{2^{*}}$

\begin{abstract}
Background: Colorectal carcinoma (CRC) with $\mathrm{CpG}$ island methylator phenotype (CIMP) is recognized as a distinct subgroup of CRC, and CIMP status affects prognosis and response to chemotherapy. Identification of CIMP status in CRC is important for proper patient management. In Eastern countries, however, the clinicopathologic and molecular characteristics and prognosis of CRCs with CIMP are still unclear.

Methods: A total of 245 patients who underwent their first surgical resection for sporadic CRC were enrolled and CIMP status of the CRCs was determined using the quantitative MethyLight assay. The clinicopathologic and molecular characteristics were reviewed and compared according to CIMP status. In addition, the three-year recurrence-free survival (RFS) of 124 patients with stage II or stage III CRC was analyzed in order to assess the effectiveness of fluoropyrimidine-based adjuvant chemotherapy with respect to CIMP status.
\end{abstract}

Results: CIMP-high CRCs were identified in 34 cases (13.9\%), and were significantly associated with proximal tumor location, poorly differentiated carcinoma, mucinous histology, and high frequencies of BRAF mutation, MGMT methylation, and MSI-high compared to CIMP-low/negative carcinomas. For patients with stage II or III CIMP-low/ negative CRCs, no significant difference was found in RFS between those undergoing surgery alone and those receiving surgery with fluoropyrimidine-based adjuvant chemotherapy. However, for patients with CIMP-high CRCs, patients undergoing surgery with fluoropyrimidine-based adjuvant chemotherapy ( $n=17$; three-year RFS: 100\%) showed significantly better RFS than patients treated with surgery alone $(n=7$; three-year RFS: 71.4\% $(P=0.022)$.

Conclusions: Our results suggest that selected patients with CIMP-high CRC may benefit from fluoropyrimidinebased adjuvant chemotherapy with longer RFS. Further large scale-studies are required to confirm our results.

\section{Background}

The epidemiology and clinicopathologic characteristics of colorectal carcinoma (CRC) in Eastern countries differ from those of Western countries in many aspects [1-3]. The distinct lifestyles and diet may underlie these differences $[4,5]$. Furthermore, recent studies have demonstrated that the molecular pathogenesis of CRC

\footnotetext{
*Correspondence: kkmkys@skku.edu; ghkang@snu.ac.kr

${ }^{2}$ Department of Pathology, Seoul National University College of Medicine, Seoul, Korea

${ }^{3}$ Department of Pathology, Samsung Medical Center, Sungkyunkwan University School of Medicine, Seoul, Korea

Full list of author information is available at the end of the article
}

in Eastern countries may be different from that of Western countries [6-8]. The prognosis and response to chemotherapy of patients with CRC may be affected by molecular characteristics [9-11], and it has been suggested that CRC treatment plans should be developed based on individual molecular characteristics. As such, identification of molecular characteristics associated with CRC has important clinical implications.

In addition to chromosomal instability and microsatellite instability (MSI), CpG island methylator phenotype (CIMP), which is characterized by the simultaneous methylation of multiple $\mathrm{CpG}$ islands, is currently

\section{C) Biomed Central}


recognized as one of the major mechanisms underlying colorectal carcinogenesis [12-14]. In this phenotype, widespread methylation of $\mathrm{CpG}$ islands results in the epigenetic inactivation of tumor suppressor genes by promoter methylation. CIMP-positive CRCs have been reported to have distinct clinicopathologic profiles compared to their CIMP-low/negative counterparts; older age, female sex, proximal tumor location, poorly differentiated or mucinous histology, and high rates of MSI and $B R A F$ mutation [12,13,15-20]. In addition, although some controversies still exist, several studies reported that CIMP status influences prognosis and response to chemotherapy in patients with CRC [21-24]. A previous study reported that CIMP positivity appears to result in improved survival among patients receiving 5-fluorouracil-based adjuvant chemotherapy for stage III CRC [22]. However, a recent large-scale study failed to demonstrate CIMP positivity as a significant prognostic factor in stage II and III CRCs treated with adjuvant chemotherapy [25]. In Eastern countries, few studies of the clinicopathologic features in CIMP-positive CRCs have been conducted $[26,27]$, and patient outcomes with respect to CIMP status have never been explored by quantitative methylation analyses.

In order to determine the clinicopathologic and molecular characteristics and recurrence-free survival (RFS) of CRC according to CIMP status, we selected Korean patients with MSI-high and MSI-low CRCs and analyzed their CIMP status by quantitative methylation analyses. The results of this study will contribute to the determination of clinicopathologic and molecular characteristics and prognoses of CRCs stratified by CIMP status in Korean patients.

\section{Methods}

\section{Patients and tumor specimens}

In order to compare methylation profiles according to MSI status, 49 MSI-high carcinomas and 196 microsatellite stable (MSS) or MSI-low carcinomas were selected from archived samples. All 245 selected patients had undergone their first surgical resection for CRC at Samsung Medical Center $(\mathrm{n}=132$; random selection after acquisition of 40 MSI-high carcinomas) or Seoul National University Hospital ( $\mathrm{n}=113$; consecutively selected) between July 2003 and October 2006.

Patients with inflammatory bowel disease, a family history of Lynch syndrome or familial adenomatous polyposis, or synchronous multiple colorectal cancers were excluded. Surgical resection techniques were standardized in the respective hospitals during the study period. Tumor stage and depth of invasion were defined according to the tumor, node, metastasis (TNM) classification developed by the American Joint Committee on Cancer [28]. Stage I was assigned in 27, II in 91, III in 82 and
IV in 45 cases. None of the patients had received chemotherapy or radiotherapy prior to surgery. During study period, adjuvant chemotherapy regimen for stage II and III CRCs was mainly based on fluoropyrimidines (5-FU or capecitabine). Mayo Clinic regimen was used for administration of 5-FU: six cycles of rapid intravenous infusion of $20 \mathrm{mg} / \mathrm{m}^{2}$ leucovorin, followed immediately by an intravenous bolus of $425 \mathrm{mg} / \mathrm{m}^{2}$ fluorouracil, on days 1 to 5 every four weeks. The palliative chemotherapy regimen for stage IV CRCs was based on fluoropyrimidines, oxaliplatin, or irinotecan.

Formalin-fixed, paraffin-embedded tissues were used for DNA extraction. DNA was extracted from $10 \mu \mathrm{m}$ sections stained with $0.1 \%$ methylene blue by manual microdissection under microscopy using 20-gauge needles and proteinase $\mathrm{K}$ solution as described previously [29]. Clinicopathologic data were collected by review of medical records and pathology slides. In the present study, tumors located from the cecum to the transverse colon were classified as proximal and those from the splenic flexure to the rectum were classified as distal.

All patients gave informed consent prior to specimen collection according to our institutional guidelines. This study was carried out in accordance with the Declaration of Helsinki. The institutional review boards at Samsung Medical Center and Seoul National University Hospital approved the study protocol.

\section{Survival analyses}

RFS data for patients with stage I, II or III CRCs was obtained by review of medical records using the intranet resources at both hospitals. RFS was measured from the date of resection to the date of the first recurrence documented by imaging or pathologic confirmation or until the censoring date of May 31, 2010.

We performed a subgroup analysis of RFS to determine the impact of fluoropyrimidine-based adjuvant chemotherapy on clinical outcome in patients with stage II and stage III CRCs with respect to CIMP status. Among the 173 patients with stage II or stage III CRCs, we excluded from analysis 20 patients who received oxaliplatin-based adjuvant chemotherapy, 15 patients with rectal cancers who received concurrent chemo-radiation therapy and 14 patients who did not undergo any follow-up examinations. A total of 124 patients with stage II or stage III CRCs were ultimately analyzed. Among them, 46 cases had undergone surgery without subsequent adjuvant chemotherapy and 78 received fluoropyrimidine-based adjuvant chemotherapy after surgery. The median follow-up time for these patients was 44.5 months (range, 6-75 months).

\section{Molecular analyses for CIMP}

Five widely used methylation markers that allow for excellent discrimination of CIMP status were employed 
in this study. This panel of markers consists of the CACNA1G, IGF2, NEUROG1, RUNX3, and SOCS1 genes [20]. The MethyLight assay (Applied Biosystems) was applied to quantitatively determine methylation status as previously described [20]. Briefly, two sets of primers and probes designed specifically for bisulfiteconverted DNA were used. Reaction specificity for methylated DNA was confirmed separately using human DNA treated with CpG methyltransferase SssI (New England Biolabs). In addition to CIMP markers, methylation of $O^{6}$-methylguanine-DNA methyltransferase (MGMT) gene was also analyzed by methylation-specific polymerase chain reaction due to its importance in KRAS mutations [30-32] and clinical significance in survival [33]. CIMP classification was based on the numbers of methylated genes in each panel. Tumors were classified as CIMP-high if three or more markers were methylated, CIMP-low if one or two markers were methylated, and CIMP-negative if a methylated marker was not observed $[14,20]$.

\section{Molecular analyses of MSI status and the presence of BRAF and KRAS mutations}

We used five microsatellite markers recommended by the National Cancer Institute Workshop on MSI to determine MSI status [34]. PCR analyses were performed using a DNA autosequencer (Applied Biosystems 373A sequencer; Applied Biosystems, CA, USA). The mobility shift of PCR products from the tumor DNA was compared to that from corresponding normal colonic mucosa. Tumors were classified as MSI-high if band shifts were observed in two or more markers compared to the control, MSI-low if shifts were observed in one marker, and MSS if no shift was observed [34]. BRAF mutations in exon 11 and exon 15 and KRAS mutations in codons 12 and 13 in exon 2 were analyzed by PCR and automated sequencing as previously described [29].

\section{Statistical analysis}

Patient clinicopathologic features were compared using the $x^{2}$ test and Student's $t$-test, with $p<0.05$ considered significant. Survival curves were analyzed by the KaplanMeier method, and differences between individual curves were evaluated by the log-rank test. Multivariate analysis using the Cox proportional hazards model was performed to explore the potential association between clinicopathologic and molecular parameters and RFS.

\section{Results}

Clinicopathologic and molecular characteristics according to the CIMP status

The characteristics of CIMP-high and CIMP-low/negative CRCs are summarized in Table 1. CIMP-high
Table 1 Clinicopathologic and molecular characteristics of colorectal cancers according to the CIMP status

\begin{tabular}{|c|c|c|c|}
\hline & $\begin{array}{l}\text { CIMP-low/negative } \\
(n=211)\end{array}$ & $\begin{array}{l}\text { CIMP-high } \\
(\mathrm{n}=34)\end{array}$ & $P$ value \\
\hline Age (yrs) & & & 0.388 \\
\hline Mean \pm SD & $59.7 \pm 11.9$ & $61.6 \pm 11.9$ & \\
\hline Median (range) & $62.0(29-83)$ & $63.5(33-82)$ & \\
\hline Gender (\%) & & & 0.752 \\
\hline Male & $118(55.9)$ & $20(58.8)$ & \\
\hline Female & $93(44.1)$ & $14(41.2)$ & \\
\hline Tumor site (\%) & & & $<0.001$ \\
\hline Proximal & $64(30.3)$ & $23(67.6)$ & \\
\hline Distal & $147(69.7)$ & $11(32.4)$ & \\
\hline Lymph node metastasis (\%) & & & 0.770 \\
\hline Absent & $106(50.2)$ & $18(52.9)$ & \\
\hline Present & $105(49.8)$ & $16(47.1)$ & \\
\hline AJCC stage (\%) & & & 0.548 \\
\hline$|/| \mid$ & $100(47.4)$ & $18(52.9)$ & \\
\hline III/IV & $111(52.6)$ & $16(47.1)$ & \\
\hline Differentiation (\%) & & & $<0.001$ \\
\hline Well/Moderate & $191(90.5)$ & $21(61.8)$ & \\
\hline Poor/Mucinous & $20(9.5)$ & $13(38.2)$ & \\
\hline Mucinous histology (\%) & & & $0.045 \ldots$ \\
\hline Absent & $202(95.7)$ & $28(82.4)$ & \\
\hline Present & $9(4.3)$ & $6(17.6)$ & \\
\hline BRAF (\%) & & & $<0.001$ \\
\hline Wild type & 209 (99.1) & $25(73.5)$ & \\
\hline Mutation & $2(0.9)$ & $9(26.5)$ & \\
\hline KRAS (\%) & & & 0.894 \\
\hline Wild type & $139(65.9)$ & $22(64.7)$ & \\
\hline Mutation & $72(34.1)$ & $12(35.3)$ & \\
\hline MGMT methylation (\%) & & & $<0.001$ \\
\hline Absent & $153(72.5)$ & $12(35.3)$ & \\
\hline Present & $58(27.5)$ & $22(64.7)$ & \\
\hline MSI status (\%) & & & $<0.001$ \\
\hline MSS/MSI-low & 183 (86.7) & 13 (38.2) & \\
\hline MSI-high & $28(13.3)$ & $21(61.8)$ & \\
\hline
\end{tabular}

CIMP CpG island methylator phenotype, AJCC American Joint Committee on Cancer, MSI microsatellite instablity, MSS microsatellite stable.

Bold numbers indicate features associated with CIMP-high colorectal cancers $p$ values $<0.05$ were adjusted with Bonferroni correction to correct for potential false positive results

carcinomas were found in 34 cases (13.9\%) and were more frequently associated with proximal tumor locations, poorly differentiated histology, mucinous histology, BRAF mutation, MGMT methylation, and MSI-high compared to CIMP-low/negative carcinomas $(P<0.05)$.

All $B R A F$ mutations were missense mutations in codon 600 of exon 15 (V600E) and BRAF and KRAS mutations were mutually exclusive. $B R A F$ mutations were found more frequently in CIMP-high $(26.5 \%)$ than in CIMP-low/negative carcinomas $(0.9 \%)$. When stratified by MSI status, BRAF mutation rates were $12.2 \%$ for MSI-high CRCs and 2.6\% for MSI-low/MSS CRCs $(P=$ 
0.010). The rates of KRAS mutations were comparable in CIMP-high (35.3\%) and CIMP-low/negative carcinomas $(34.1 \%)$. When stratified by MSI status, KRAS mutation rates were $28.6 \%$ for MSI-high CRCs and $35.7 \%$ for MSI-low/MSS CRCs $(P=0.346)$. KRAS mutation was significantly more prevalent in carcinomas with MGMT methylation (46.3\%) than in cases without MGMT methylation (46.3\% vs. $28.5 \% ; P=0.006$ ).

Survival analyses in patients with stage I, II, and III CRCs There were a total of 200 patients with stage I, II, and III CRCs, and the three-year RFS survival for each stage was $91.6 \%, 88.0 \%$, and $71.6 \%$, respectively. In these patients, RFS did not differ significantly between CIMPhigh and CIMP-low/negative groups (three-year RFS: $89.0 \%$ vs. $80.6 \%$; $P=0.274)$. Regarding MSI, patients with MSI-high CRCs showed longer RFS than those with MSI-low or MSS CRCs, although this difference did not reach statistical significance (three-year RFS: 90.6\% vs. $79.2 \% ; P=0.069$ ).

On multivariate analysis of RFS of patients with stage I, II or stage III CRCs, TNM stage was an independent predictor of recurrence (Table 2). We performed an additional multivariate analysis of RFS for the 124 patients with stage II or stage III CRCs who had undergone surgery only or received fluoropyrimidine-based adjuvant chemotherapy after surgery. The following variables were included in the multivariate model: age, gender, TNM stage, histological differentiation, CIMP status, MSI status, treatment modality (surgery alone versus surgery with chemotherapy), BRAF mutation, KRAS mutation and MGMT methylation. Only TNM stage was identified as an independent predictor of RFS in these patients (hazard ratio: 5.963, 95\% CI: 1.351 26.314). As no recurrence occurred in patients with CIMP-high CRCs treated with fluoropyrimidine-based adjuvant chemotherapy, the effect of an interaction between CIMP status and treatment modality in these patients could not be analyzed using the Cox proportional hazards model.

Survival analyses according to CIMP status and treatment modality in patients with stage II or III CRCs

To explore the impact of fluoropyrimidine-based adjuvant chemotherapy for stage II and stage III CRCs according to CIMP status, we analyzed the RFS of 124 patients with stage II or stage III CRCs. The RFS was not significantly different between CIMP-high group and CIMP-low/negative group (three-year RFS: $91.7 \%$ vs. $84.0 \% ; P=0.31$ ). In addition, RFS was not significantly affected by treatment modality. The three-year RFS for patients who received surgery alone and those who underwent surgery followed by fluoropyrimidinebased adjuvant chemotherapy was $84.1 \%$ and $86.5 \%$,
Table 2 Multivariate analysis of recurrence-free survival in patients with stage I-III colon cancers

\begin{tabular}{|c|c|c|c|}
\hline & & $\begin{array}{c}\text { Univariate HR } \\
(95 \% \mathrm{Cl})\end{array}$ & $\begin{array}{c}\text { Multivariate } \\
\text { HR } \\
(95 \% \mathrm{Cl})\end{array}$ \\
\hline Age & & $\begin{array}{c}1.015(0.985- \\
1.047)\end{array}$ & $\begin{array}{c}1.028(0.995- \\
1.062)\end{array}$ \\
\hline \multirow[t]{2}{*}{ Sex } & Male & 1 (referent) & 1 (referent) \\
\hline & Female & $\begin{array}{c}1.438(0.733- \\
2.819)\end{array}$ & $\begin{array}{c}1.600(0.799- \\
3.204)\end{array}$ \\
\hline \multirow[t]{2}{*}{ Stage } & Stage $|/| \mid$ & 1 (referent) & 1 (referent) \\
\hline & Stage III & $\begin{array}{c}2.303(1.163- \\
4.561)\end{array}$ & $\begin{array}{c}2.587(1.267- \\
5.281)\end{array}$ \\
\hline \multirow[t]{2}{*}{ Differentiation } & Well/Moderate & 1 (referent) & 1 (referent) \\
\hline & Poor/Mucinous & $\begin{array}{c}1.210(0.426- \\
3.435)\end{array}$ & $\begin{array}{c}1.347(0.415- \\
4.375)\end{array}$ \\
\hline \multirow[t]{2}{*}{ CIMP } & $\begin{array}{l}\text { CIMP-low/ } \\
\text { negative }\end{array}$ & 1 (referent) & 1 (referent) \\
\hline & CIMP-high & $\begin{array}{c}0.523(0.160- \\
1.710)\end{array}$ & $\begin{array}{c}0.806(0.207- \\
3.136)\end{array}$ \\
\hline \multirow[t]{2}{*}{ MSI } & MSI-low/MSS & 1 (referent) & 1 (referent) \\
\hline & MSI-high & $\begin{array}{c}0.394(0.139- \\
1.118)\end{array}$ & $\begin{array}{c}0.485(0.139- \\
1.701)\end{array}$ \\
\hline \multirow[t]{2}{*}{ BRAF mutation } & No & 1 (referent) & 1 (referent) \\
\hline & Yes & No recurrence & No recurrence \\
\hline \multirow[t]{2}{*}{ KRAS mutation } & No & 1 (referent) & 1 (referent) \\
\hline & Yes & $\begin{array}{c}1.096(0.542- \\
2.214)\end{array}$ & $\begin{array}{c}1.185(0.568- \\
2.471)\end{array}$ \\
\hline \multirow{2}{*}{$\begin{array}{l}\text { MGMT } \\
\text { methylation }\end{array}$} & No & 1 (referent) & 1 (referent) \\
\hline & Yes & $\begin{array}{c}0.667(0.311- \\
1.429)\end{array}$ & $\begin{array}{c}0.703(0.304- \\
1.628)\end{array}$ \\
\hline
\end{tabular}

$H R$ hazard ratio, CIMP CpG island methylator phenotype, MSI microsatellite instability, MSS microsatellite stable

respectively $(P=0.387)$. Patients with MSI-high CRCs experienced longer RFS compared to those with MSIlow or MSS CRCs, although this difference did not reach statistical significance (three-year RFS: $94.0 \%$ vs. 82.3\%; $P=0.088$ ).

Figure 1 shows RFS according to CIMP status in patients who underwent surgery alone (Figure 1A) and in patients who received fluoropyrimidine-based adjuvant chemotherapy after surgery (Figure 1B) for stage II or III CRCs. In patients treated with surgery alone (Figure 1A), RFS did not differ significantly between CIMPhigh and CIMP-low/negative groups. However, in patients treated with surgery and fluoropyrimidine-based adjuvant chemotherapy (Figure 1B), CIMP-high group had a longer RFS than the CIMP-low/negative group although this difference did not reach statistical significance (three-year RFS: $100 \%$ vs. $82.4 \% ; P=0.073$ ).

Since our results suggested an interaction between CIMP-high status and fluoropyrimidine-based chemotherapy in stage II or III CRCs, we performed survival analyses according to treatment modality in patients with CIMP-low/negative (Figure 2A) and CIMP-high 

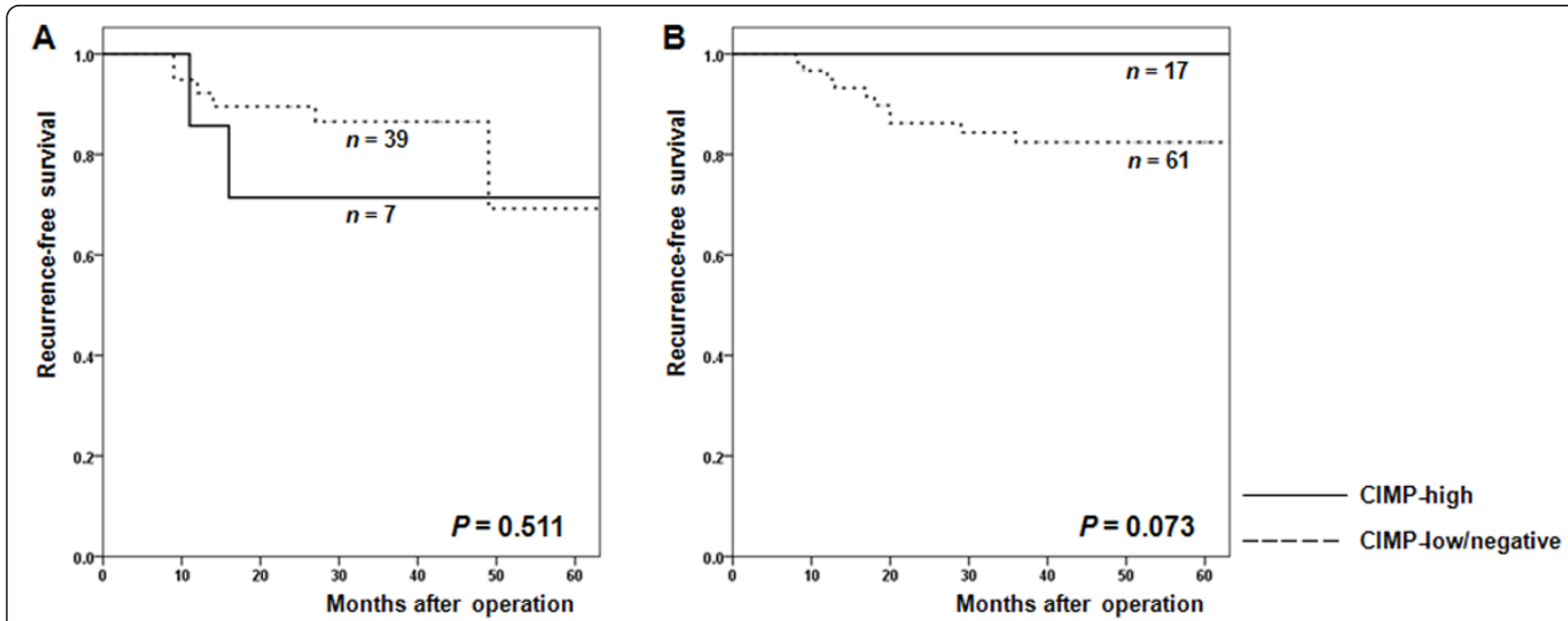

Figure 1 Recurrence-free survival (RFS) of stage II-III colorectal cancer patients according to the CpG island methylation phenotype (CIMP). (A) Kaplan-Meier curves for RFS of patients treated by surgery alone. The three-year RFS for CIMP-high and CIMP-low/negative groups was $71.4 \%$ and $86.5 \%$, respectively. (B) Kaplan-Meier curves for the RFS of patients treated with surgery and fluoropyrimidine-based adjuvant chemotherapy. The three-year RFS for CIMP-high and CIMP-low/negative groups was 100\% and $82.4 \%$, respectively.

CRCs (Figure 2B). The characteristics of these patients according to CIMP status and treatment modality are summarized in Table 3 . In both patients with CIMPlow/negative and patients with CIMP-high CRCs, those undergoing surgery followed by chemotherapy showed a higher LN metastasis rate and consequently a more advanced TNM stage than those undergoing surgery alone $(P<0.001$ for CIMP-low/negative CRCs; $P=$ 0.352 for CIMP-high CRCs). In patients with stage II or III CIMP-low/negative CRCs (Figure 2A), RFS was not significantly different between those undergoing surgery alone and those receiving surgery with adjuvant chemotherapy. When stratified according to TNM stage, a similar trend was observed for both stage II and stage III CRCs (Figure 3A and 3C). However, in patients with stage II or III CIMP-high CRCs (Figure 2B), the RFS of those treated with surgery and fluoropyrimidine-based adjuvant chemotherapy was significantly higher than that of patients treated with surgery alone (three-year RFS: $100 \%$ vs. $71.4 \% ; P=0.022$ ). Figures $3 \mathrm{~B}$ and $3 \mathrm{D}$ show the RFS for patients with stage II and stage III CIMP-high CRCs, respectively. In both stages, patients
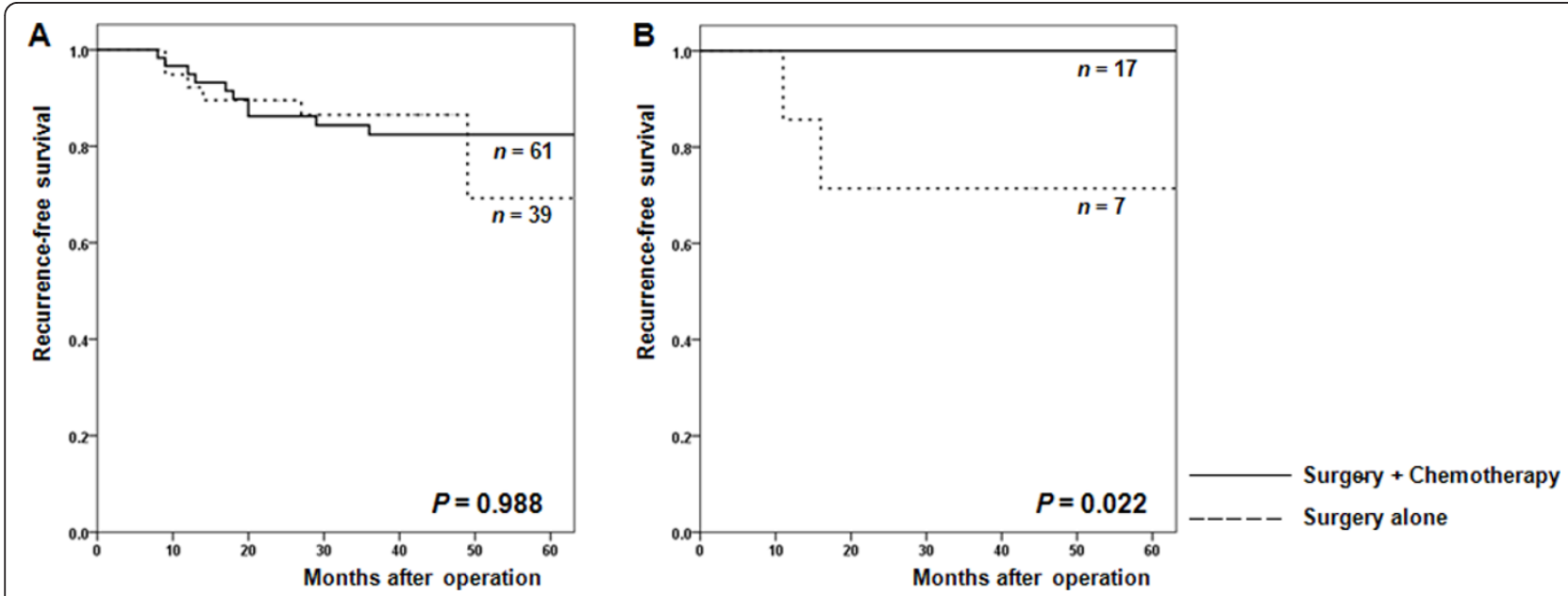

Figure 2 Recurrence-free survival (RFS) of stage II-III colorectal cancer patients according to treatment. (A) Kaplan-Meier curves for the RFS of patients with the CPG island methylation phenotype (CIMP)-low/negative CRCs. The three-year RFS for patients treated by surgery with adjuvant chemotherapy and those treated by surgery alone was $82.4 \%$ and $86.5 \%$, respectively. (B) Kaplan-Meier curves for the RFS of patients with CIMP-high CRCs. The three-year RFS for the surgery with adjuvant chemotherapy group and the surgery alone group was $100 \%$ and $71.4 \%$, respectively. 
Table 3 Clinicopathologic and molecular characteristics of colorectal cancers in patients with stage II or stage III colorectal cancers who underwent surgery alone or received fluoropyrimidine-based adjuvant chemotherapy

\begin{tabular}{|c|c|c|c|c|}
\hline & $\begin{array}{l}\text { CIMP-low/negative } \\
\text { Surgery alone } \\
(\mathrm{n}=39)\end{array}$ & $\begin{array}{c}\text { CIMP-low/negative } \\
\text { Surgery + CRx } \\
(n=61)\end{array}$ & $\begin{array}{l}\text { CIMP-high } \\
\text { Surgery alone } \\
(n=7)\end{array}$ & $\begin{array}{c}\text { CIMP-high } \\
\text { Surgery + CRx } \\
(n=17)\end{array}$ \\
\hline \multicolumn{5}{|l|}{ Age (yrs) } \\
\hline Mean \pm SD & $63.4 \pm 11.0$ & $58.7 \pm 10.8$ & $72.9 \pm 7.1$ & $60.1 \pm 10.7$ \\
\hline Median (Range) & $66.0(42-83)$ & $64.0(36-75)$ & $75.0(63-82)$ & $63.0(33-72)$ \\
\hline \multicolumn{5}{|l|}{ Gender (\%) } \\
\hline Male & $23(59.0)$ & $34(55.7)$ & $3(42.9)$ & $11(64.7)$ \\
\hline Female & $16(41.0)$ & $27(44.3)$ & $4(57.1)$ & $6(35.3)$ \\
\hline \multicolumn{5}{|l|}{ Tumor site (\%) } \\
\hline Proximal & $14(35.9)$ & 19 (31.1) & $6(85.7)$ & $12(70.6)$ \\
\hline Distal & $25(64.1)$ & $42(68.9)$ & $1(14.3)$ & $5(29.4)$ \\
\hline \multicolumn{5}{|c|}{ Lymph node metastasis (\%) } \\
\hline Absent & 37 (94.9) & $25(41.0)$ & $6(85.7)$ & $10(58.8)$ \\
\hline Present & $2(5.1)$ & $36(59.0)$ & $1(14.3)$ & $7(41.2)$ \\
\hline \multicolumn{5}{|l|}{ AJCC stage (\%) } \\
\hline$\|$ & $37(94.9)$ & $25(41.0)$ & $6(85.7)$ & $10(58.8)$ \\
\hline III & $2(5.1)$ & $36(59.0)$ & $1(14.3)$ & $7(41.2)$ \\
\hline \multicolumn{5}{|l|}{ Differentiation (\%) } \\
\hline Well/Moderate & $34(87.2)$ & $56(91.8)$ & $6(85.7)$ & $9(52.9)$ \\
\hline Poor/Mucinous & $5(12.8)$ & $5(8.2)$ & $1(14.3)$ & $8(47.1)$ \\
\hline \multicolumn{5}{|c|}{ Mucinous histology (\%) } \\
\hline Absent & $36(92.3)$ & $59(96.7)$ & $7(100.0)$ & $12(70.6)$ \\
\hline Present & $3(7.7)$ & $2(3.3)$ & $0(0.0)$ & $5(29.4)$ \\
\hline \multicolumn{5}{|l|}{ BRAF (\%) } \\
\hline Wild type & $39(100.0)$ & $61(100.0)$ & $4(57.1)$ & $14(82.4)$ \\
\hline Mutation & $0(0.0)$ & $0(0.0)$ & $3(42.9)$ & $3(17.6)$ \\
\hline \multicolumn{5}{|l|}{ KRAS (\%) } \\
\hline Wild type & $22(56.4)$ & $45(73.8)$ & $3(42.9)$ & $11(64.7)$ \\
\hline Mutation & 17 (43.6) & $16(26.2)$ & $4(57.1)$ & $6(35.3)$ \\
\hline \multicolumn{5}{|l|}{ MGMT methylation (\%) } \\
\hline Absent & $26(66.7)$ & $47(77.0)$ & $3(42.9)$ & $5(29.4)$ \\
\hline Present & $13(33.3)$ & $14(23.0)$ & $4(57.1)$ & $12(70.6)$ \\
\hline \multicolumn{5}{|l|}{ MSI status (\%) } \\
\hline MSS/MSI-low & $33(84.6)$ & $50(82.0)$ & $4(57.1)$ & $3(17.6)$ \\
\hline MSI-high & $6(15.4)$ & $11(18.0)$ & $3(42.9)$ & $14(82.4)$ \\
\hline
\end{tabular}

CIMP CpG island methylator phenotype, CRx Fluoropyrimidine-based adjuvant chemotherapy

MSI microsatellite instablity, MSS microsatellite stable

receiving adjuvant chemotherapy demonstrated longer RFS than those receiving surgery alone.

\section{Discussion}

CIMP is recognized as one of the major pathways in colorectal carcinogenesis [12-14]. Recent studies have demonstrated that the molecular pathogenesis of CRCs may differ according to ethnic background [6-8]. Studies of CIMP CRCs in Eastern countries are rare and the relationship between CIMP and survival or treatment modality has not been described [26,27]. CIMP-high CRCs were found to be associated with older age, female sex, proximal tumor location, poorly differentiated or mucinous histology, and higher frequencies of MSI-high and BRAF mutation [12,13,15-20], and nearly all of these characteristics are similar to those of MSI-high carcinomas $[34,35]$. In the present study, we also found that CIMP-high CRCs were more frequently associated with proximal tumor location, poorly differentiated histology, mucinous histology, BRAF mutation, and MSI-high status compared to their CIMP-low/negative counterparts.

Although most of the clinicopathologic features associated with CIMP are consistent with previous reports, the frequency of BRAF mutations observed in the present study (26.5\% of CIMP-high CRCs) was much lower than that reported by studies of patients from 


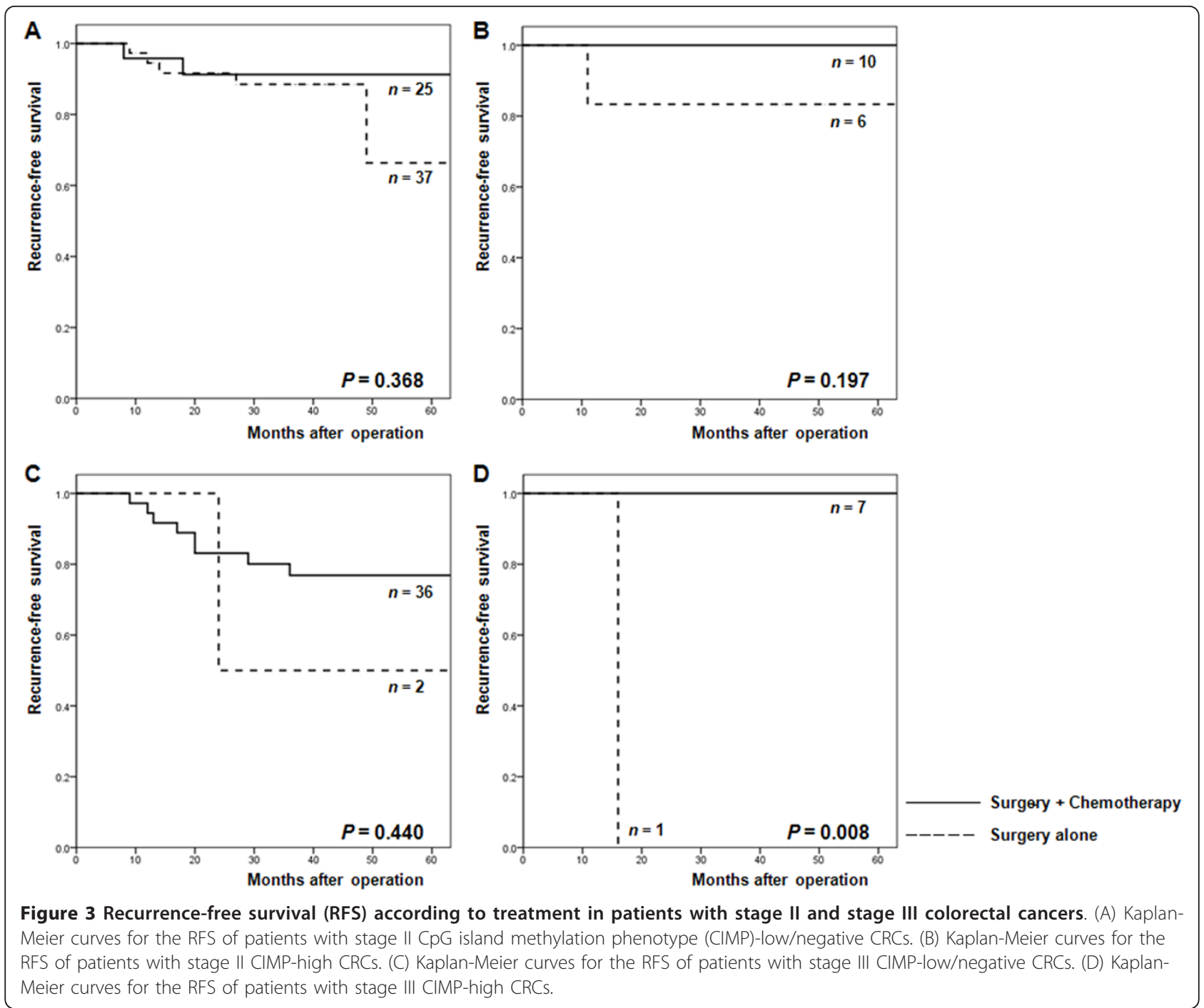

Western populations (60-70\% of CIMP-high CRCs) (Table 4) [20,36,37]. These same studies found BRAF mutation frequencies ranging from $48.6 \%$ to $76.1 \%$ in MSI-high CRCs (Table 3) $[20,36,37]$. In the present study, however, BRAF mutation rate was only $12.2 \%$ for MSI-high CRCs, which was consistent with a previous report for patients of the same ethnic background (10.5\% among MSI-high carcinomas) [27]. Recently, we performed a study directly comparing the molecular features of sessile serrated adenoma, which is a potential precursor of CIMP-high CRCs, from Korean and Western populations. In that study, both $B R A F$ mutation ( $40 \%$ versus $80 \%$ ) and $h M L H 1$ methylation (25\% versus $45 \%$ ) found in sessile serrated adenomas were less frequent in Korea than in the USA. Therefore, it is possible that the lower rate of $B R A F$ mutation observed in CIMP-high CRCs in Korea is established from the precursor level [38].

Table 4 BRAF mutation and KRAS mutation rates according to CIMP and MSI status

\begin{tabular}{|c|c|c|c|c|c|c|c|c|c|c|}
\hline & \multicolumn{2}{|c|}{ Present study } & \multicolumn{2}{|c|}{ Lee et al. [27] } & \multicolumn{2}{|c|}{ Weisenberger et al. [20] } & \multicolumn{2}{|c|}{ Ogino et al. [37] } & \multicolumn{2}{|c|}{ Kambara et al. [36] } \\
\hline & BRAF (\%) & KRAS (\%) & BRAF (\%) & KRAS (\%) & BRAF (\%) & KRAS (\%) & BRAF (\%) & KRAS (\%) & BRAF (\%) & KRAS (\%) \\
\hline CIMP-low/negative & 0.9 & 34.1 & 1.1 & 31.5 & 1.3 & 35.4 & 6.2 & 41.6 & 10.3 & 37.2 \\
\hline CIMP-high & 26.5 & 35.3 & 11.9 & 38.1 & 72.7 & 9.7 & 61.2 & 7.5 & 76.9 & 15.4 \\
\hline MSI-low/MSS & 2.6 & 35.7 & 3.4 & & & & 8.9 & 41.3 & 8.6 & 44.4 \\
\hline MSI-high & 12.2 & 28.6 & 10.5 & & & & 48.6 & 10.0 & 76.1 & 2.2 \\
\hline
\end{tabular}

CIMP CpG island methylator phenotype, MSI microsatellite instability, MSS microsatellite stable 
CIMP status reportedly affects the prognosis and response to chemotherapy in patients with CRC [21-24]; however, the effect of CIMP status on prognosis is still controversial. A previous study reported that CIMP-high carcinomas appeared to result in improved survival among patients who received 5-fluorouracil-based adjuvant chemotherapy [22]. In contrast, other studies reported worse survival in CIMP-high tumors compared to CIMP-low/negative carcinomas [23,25]. In this first study with different ethnic background, we found that patients with CIMP-high CRC treated with surgery and fluoropyrimidine-based adjuvant chemotherapy demonstrated significantly longer RFS than did CIMP-high CRC patients treated with surgery alone despite their higher frequency of LN metastasis and more advanced TNM stage. These observations are consistent with the previous study[22]. Because MSI-high patients show better survival compared to MSS/MSI-low patients $[34,35]$, the observed better survival in patients with CRC treated with surgery and adjuvant chemotherapy may have been affected by the higher frequency of MSI-high CRCs in this patient group (82.4\% versus $42.9 \%)$. So, additional large-scale studies are required to confirm our results.

The relationship between CIMP-high CRCs and responsiveness to 5-FU-based chemotherapy has also been reported [22,39]. Intracellular folate concentrations are known to be critically important in determining response to 5-FU $[40,41]$. As CIMP-high CRCs show higher levels of 5-10-methylene tetrahydrofolate $\left(\mathrm{CH}_{2} \mathrm{FH}_{4}\right.$ ) and $\mathrm{FH}_{4}$ compared to CIMP-low/negative CRCs [42], the higher level of folate in CIMP-high CRCs may be a plausible explanation for better response to 5-FU in these patients. Additionally, $\gamma$-glutamyl hydrolase, an enzyme that removes glutamates and lowers intracellular folate levels, is expressed in significantly lower levels in CIMP-high CRCs compared to CIMP-low/negative CRCs [43,44], and reduced expression of $\gamma$-glutamyl hydrolase is associated with a favorable response to 5-FU-based chemotherapy in patients with metastatic CRCs [45]. Moreover, methylation-induced silencing of dihydropyrimidine dehydrogenase, the rate-limiting enzyme in 5-FU degradation, may also provide a link between CIMP-high CRCs and favorable response to 5-FU [46-48].

The present study had several limitations. The sample size for the RFS analysis was small and there is the potential for selection bias because the cases were neither prospectively recruited nor randomized to receive adjuvant chemotherapy. In addition, the selection of CRCs according to MSI status may represent an additional source of bias in this study. Despite these limitations, we were able to demonstrate that the clinicopathologic and molecular characteristics were distinct and prognoses were different between the methylation subgroups. A large-scale, prospective, randomized study would be ideal to definitively determine the impact of fluoropyrimidine-based adjuvant chemotherapy for stage II and stage III CRCs with respect to CIMP status. However, it is practically impossible to perform this kind of study as adjuvant chemotherapy is now recognized as a standard therapy and patients with stage II and III CRCs not receiving chemotherapy are very rare. In addition, oxaliplatin-based chemotherapy such as FOLFOX has recently replaced fluoropyrimidine-based chemotherapy as the standard adjuvant chemotherapy regimen.

\section{Conclusions}

Our results confirm that CIMP-high CRCs demonstrate distinct clinicopathologic and molecular characteristics even in a different ethnic background from Western countries. In addition, our results indicate that CIMPhigh tumors appear to benefit from fluoropyrimidinebased adjuvant chemotherapy. Confirmation of these findings with additional large-scale studies may lead to the improved selection of CRC patients to receive fluoropyrimidine-based adjuvant chemotherapy.

\section{List of Abbreviations}

CIMP: CpG island methylator phenotype; $\mathrm{CRC}$ : colorectal carcinoma; $\mathrm{CH}_{2} \mathrm{FH}_{4}$ : 5-10-methylene tetrahydrofolate; MSI: microsatellite instability; MSS: microsatellite stable.

\section{Acknowledgements and Funding}

This work was supported by a grant of the Korea Healthcare Technology R\&D Project, Ministry for Health, Welfare \& Family Affairs (A091081; to GHK) and by National Research Foundation of Korea (NRF) Grant funded by the Korean Government (2011-0003996; to GHK).

\section{Author details}

'Departments of Medicine, Samsung Medical Center, Sungkyunkwan University School of Medicine, Seoul, Korea. ${ }^{2}$ Department of Pathology, Seoul National University College of Medicine, Seoul, Korea. ${ }^{3}$ Department of Pathology, Samsung Medical Center, Sungkyunkwan University School of Medicine, Seoul, Korea. ${ }^{4}$ Department of Surgery, Samsung Medical Center, Sungkyunkwan University School of Medicine, Seoul, Korea. ${ }^{5}$ Department of Pathology, Daehang Hospital, Seoul, Korea.

\section{Authors' contributions}

BHM designed the study, analyzed the data and drafted the manuscript. JMB and HSY collected and analyzed the data. EJL carried out the molecular genetic studies. YHK, DKC, and HCK provided the samples. CKP and SHL reviewed the pathology specimens. KMK designed the study, reviewed the pathology specimens, and critically revised the manuscript. GHK designed the study, reviewed the pathology specimens and critically revised the manuscript. All authors read and approved the final manuscript.

\section{Declaration of Competing interests}

The authors declare that they have no competing interests.

Received: 28 March 2011 Accepted: 10 August 2011

Published: 10 August 2011

\section{References}

1. Chien C, Morimoto LM, Tom J, Li Cl: Differences in colorectal carcinoma stage and survival by race and ethnicity. Cancer 2005, 104:629-639. 
2. Soliman AS, Bondy ML, Levin B, Hamza MR, Ismail K, Ismail S, Hammam HM, el-Hattab OH, Kamal SM, Soliman AG, et al: Colorectal cancer in Egyptian patients under 40 years of age. Int $J$ Cancer 1997, 71:26-30.

3. Clegg LX, Li FP, Hankey BF, Chu K, Edwards BK: Cancer survival among US whites and minorities: a SEER (Surveillance, Epidemiology, and End Results) Program population-based study. Arch Intern Med 2002, 162:1985-1993.

4. Ishibe N, Freedman AN: Understanding the interaction between environmental exposures and molecular events in colorectal carcinogenesis. Cancer Invest 2001, 19:524-539.

5. Chiu BC, Ji BT, Dai Q, Gridley G, McLaughlin JK, Gao YT, Fraumeni JF Jr, Chow WH: Dietary factors and risk of colon cancer in Shanghai, China. Cancer Epidemiol Biomarkers Prev 2003, 12:201-208.

6. Soliman AS, Bondy ML, El-Badawy SA, Mokhtar N, Eissa S, Bayoumy S, Seifeldin IA, Houlihan PS, Lukish JR, Watanabe T, et al: Contrasting molecular pathology of colorectal carcinoma in Egyptian and Western patients. Br J Cancer 2001, 85:1037-1046.

7. Chan AO, Soliman AS, Zhang Q, Rashid A, Bedeir A, Houlihan PS, Mokhtar N, Al-Masri N, Ozbek U, Yaghan R, et al: Differing DNA methylation patterns and gene mutation frequencies in colorectal carcinomas from Middle Eastern countries. Clin Cancer Res 2005, 11:8281-8287.

8. Tenesa A, Farrington SM, Prendergast JG, Porteous ME, Walker M, Haq N, Barnetson RA, Theodoratou E, Cetnarskyj R, Cartwright N, et al: Genomewide association scan identifies a colorectal cancer susceptibility locus on 11q23 and replicates risk loci at 8q24 and 18q21. Nat Genet 2008.

9. Samowitz WS, Sweeney C, Herrick J, Albertsen H, Levin TR, Murtaugh MA, Wolff RK, Slattery ML: Poor survival associated with BRAF V600E mutation in microsatellite-stable colon cancers. Cancer Res 2005, 65:6063-6069.

10. Watanabe T, Wu TT, Catalano PJ, Ueki T, Satriano R, Haller DG, Benson AB, Hamilton SR: Molecular predictors of survival after adjuvant chemotherapy for colon cancer. N Engl J Med 2001, 344:1196-1206.

11. Ribic CM, Sargent DJ, Moore MJ, Thibodeau SN, French AJ, Goldberg RM, Hamilton SR, Laurent-Puig P, Gryfe R, Shepherd LE, et al: Tumor microsatellite-instability status as a predictor of benefit from fluorouracil-based adjuvant chemotherapy for colon cancer. N Engl J Med 2003, 349:247-257.

12. Jass JR: Classification of colorectal cancer based on correlation of clinical, morphological and molecular features. Histopathology 2007, 50:113-130.

13. Issa JP: CpG island methylator phenotype in cancer. Nat Rev Cancer 2004, 4:988-993.

14. Toyota M, Ahuja N, Ohe-Toyota M, Herman JG, Baylin SB, Issa JP: CpG island methylator phenotype in colorectal cancer. Proc Natl Acad Sci USA 1999, 96:8681-8686.

15. Hawkins N, Norrie M, Cheong K, Mokany E, Ku SL, Meagher A, O'Connor T, Ward R: CpG island methylation in sporadic colorectal cancers and its relationship to microsatellite instability. Gastroenterology 2002, 122:1376-1387.

16. van Rijnsoever M, Grieu F, Elsaleh H, Joseph D, lacopetta B: Characterisation of colorectal cancers showing hypermethylation at multiple CpG islands. Gut 2002, 51:797-802.

17. Rashid A, Issa JP: CpG island methylation in gastroenterologic neoplasia: a maturing field. Gastroenterology 2004, 127:1578-1588.

18. Samowitz WS, Albertsen H, Herrick J, Levin TR, Sweeney C, Murtaugh MA, Wolff RK, Slattery ML: Evaluation of a large, population-based sample supports a $\mathrm{CpG}$ island methylator phenotype in colon cancer. Gastroenterology 2005, 129:837-845.

19. Issa JP, Shen L, Toyota M: CIMP, at last. Gastroenterology 2005, 129:1121-1124.

20. Weisenberger DJ, Siegmund KD, Campan M, Young J, Long TI, Faasse MA, Kang GH, Widschwendter M, Weener D, Buchanan D, et al: CpG island methylator phenotype underlies sporadic microsatellite instability and is tightly associated with BRAF mutation in colorectal cancer. Nat Genet 2006, 38:787-793.

21. Issa JP: Methylation and prognosis: of molecular clocks and hypermethylator phenotypes. Clin Cancer Res 2003, 9:2879-2881.

22. Van Rijnsoever M, Elsaleh H, Joseph D, McCaul K, lacopetta B: CpG island methylator phenotype is an independent predictor of survival benefit from 5-fluorouracil in stage III colorectal cancer. Clin Cancer Res 2003, 9:2898-2903.
23. Ogino S, Meyerhardt JA, Kawasaki T, Clark JW, Ryan DP, Kulke MH, Enzinger PC, Wolpin BM, Loda M, Fuchs CS: CpG island methylation, response to combination chemotherapy, and patient survival in advanced microsatellite stable colorectal carcinoma. Virchows Arch 2007, 450:529-537.

24. Shen L, Catalano PJ, Benson AB, O'Dwyer P, Hamilton SR, Issa JP: Association between DNA methylation and shortened survival in patients with advanced colorectal cancer treated with 5-fluorouracil based chemotherapy. Clin Cancer Res 2007, 13:6093-6098.

25. Ward RL, Cheong K, Ku SL, Meagher A, O'Connor T, Hawkins NJ: Adverse prognostic effect of methylation in colorectal cancer is reversed by microsatellite instability. J Clin Oncol 2003, 21:3729-3736

26. Lee S, Cho NY, Yoo EJ, Kim JH, Kang GH: CpG island methylator phenotype in colorectal cancers: comparison of the new and classic CpG island methylator phenotype marker panels. Arch Pathol Lab Med 2008, 132:1657-1665

27. Lee S, Cho NY, Choi M, Yoo EJ, Kim JH, Kang GH: Clinicopathological features of $\mathrm{CpG}$ island methylator phenotype-positive colorectal cancer and its adverse prognosis in relation to KRAS/BRAF mutation. Pathol Int 2008, 58:104-113.

28. Greene FL, Page DL, Fleming ID, Fritz AG, Balch CM, Haller DG, Morrow M: AJCC cancer staging manual. 6 edition. New York: Springer-Verlag; 2002.

29. Dong SM, Lee EJ, Jeon ES, Park CK, Kim KM: Progressive methylation during the serrated neoplasia pathway of the colorectum. Mod Pathol 2005, 18:170-178.

30. Esteller M, Toyota M, Sanchez-Cespedes M, Capella G, Peinado MA, Watkins DN, Issa JP, Sidransky D, Baylin SB, Herman JG: Inactivation of the DNA repair gene O6-methylguanine-DNA methyltransferase by promoter hypermethylation is associated with $\mathrm{G}$ to $\mathrm{A}$ mutations in $\mathrm{K}$-ras in colorectal tumorigenesis. Cancer Res 2000, 60:2368-2371.

31. Shen L, Kondo Y, Rosner GL, Xiao L, Hernandez NS, Vilaythong J, Houlihan PS, Krouse RS, Prasad AR, Einspahr JG, et al: MGMT promoter methylation and field defect in sporadic colorectal cancer. J Natl Cancer Inst 2005, 97:1330-1338.

32. Ogino S, Kawasaki T, Kirkner GJ, Suemoto Y, Meyerhardt JA, Fuchs CS: Molecular correlates with MGMT promoter methylation and silencing support CpG island methylator phenotype-low (CIMP-low) in colorectal cancer. Gut 2007, 56:1564-1571.

33. Nagasaka T, Sharp GB, Notohara K, Kambara T, Sasamoto H, Isozaki H, MacPhee DG, Jass JR, Tanaka N, Matsubara N: Hypermethylation of O6methylguanine-DNA methyltransferase promoter may predict nonrecurrence after chemotherapy in colorectal cancer cases. Clin Cancer Res 2003, 9:5306-5312.

34. Boland CR, Thibodeau SN, Hamilton SR, Sidransky D, Eshleman JR, Burt RW, Meltzer SJ, Rodriguez-Bigas MA, Fodde R, Ranzani GN, Srivastava S: A National Cancer Institute Workshop on Microsatellite Instability for cancer detection and familial predisposition: development of international criteria for the determination of microsatellite instability in colorectal cancer. Cancer Res 1998, 58:5248-5257.

35. Soreide $K$, Janssen EA, Soiland $H$, Korner $H$, Baak JP: Microsatellite instability in colorectal cancer. Br J Surg 2006, 93:395-406.

36. Kambara T, Simms LA, Whitehall VL, Spring KJ, Wynter CV, Walsh MD, Barker MA, Arnold S, McGivern A, Matsubara N, et al: BRAF mutation is associated with DNA methylation in serrated polyps and cancers of the colorectum. Gut 2004, 53:1137-1144.

37. Ogino S, Cantor M, Kawasaki T, Brahmandam M, Kirkner GJ, Weisenberger DJ, Campan M, Laird PW, Loda M, Fuchs CS: CpG island methylator phenotype (CIMP) of colorectal cancer is best characterised by quantitative DNA methylation analysis and prospective cohort studies. Gut 2006, 55:1000-1006.

38. Kim KM, Lee EJ, Ha S, Kang SY, Jang KT, Park CK, Kim JY, Kim YH, Chang DK, Odze RD: Molecular features of colorectal hyperplastic polyps and sessile serrated adenoma/polyps from Korea. Am J Surg Pathol 2011.

39. lacopetta B, Kawakami K, Watanabe T: Predicting clinical outcome of 5fluorouracil-based chemotherapy for colon cancer patients: is the CpG island methylator phenotype the 5-fluorouracil-responsive subgroup? Int J Clin Oncol 2008, 13:498-503.

40. Van Triest B, Pinedo HM, Giaccone G, Peters GJ: Downstream molecular determinants of response to 5 -fluorouracil and antifolate thymidylate synthase inhibitors. Ann Oncol 2000, 11:385-391. 
41. van der Wilt CL, Backus HH, Smid K, Comijn L, Veerman G, Wouters D, Voorn DA, Priest DG, Bunni MA, Mitchell F, et al: Modulation of both endogenous folates and thymidine enhance the therapeutic efficacy of thymidylate synthase inhibitors. Cancer Res 2001, 61:3675-3681.

42. Kawakami K, Ruszkiewicz A, Bennett G, Moore J, Watanabe G, lacopetta B: The folate pool in colorectal cancers is associated with DNA hypermethylation and with a polymorphism in methylenetetrahydrofolate reductase. Clin Cancer Res 2003, 9:5860-5865.

43. Ferracin M, Gafa R, Miotto E, Veronese A, Pultrone C, Sabbioni S, Lanza G, Negrini M: The methylator phenotype in microsatellite stable colorectal cancers is characterized by a distinct gene expression profile. J Pathol 2008, 214:594-602.

44. Kawakami K, Ooyama A, Ruszkiewicz A, Jin M, Watanabe G, Moore J, Oka T, lacopetta B, Minamoto T: Low expression of gamma-glutamyl hydrolase mRNA in primary colorectal cancer with the CpG island methylator phenotype. Br J Cancer 2008, 98:1555-1561.

45. Nakajima TE, Yamada Y, Shimoda T, Matsubara J, Kato K, Hamaguchi T, Shimada Y, Okayama Y, Oka T, Shirao K: Combination of O6methylguanine-DNA methyltransferase and thymidylate synthase for the prediction of fluoropyrimidine efficacy. Eur J Cancer 2008, 44:400-407.

46. Noguchi T, Tanimoto K, Shimokuni T, Ukon K, Tsujimoto H, Fukushima M, Kawahara K, Hiyama K, Nishiyama M: Aberrant methylation of DPYD promoter, DPYD expression, and cellular sensitivity to 5-fluorouracil in cancer cells. Clin Cancer Res 2004, 10:7100-7107.

47. Zhang X, Soong R, Wang K, Li L, Davie JR, Guarcello V, Diasio RB: Suppression of DPYD expression in RKO cells via DNA methylation in the regulatory region of the DPYD promoter: a potentially important epigenetic mechanism regulating DPYD expression. Biochem Cell Biol 2007, 85:337-346.

48. Ezzeldin HH, Lee AM, Mattison LK, Diasio RB: Methylation of the DPYD promoter: an alternative mechanism for dihydropyrimidine dehydrogenase deficiency in cancer patients. Clin Cancer Res 2005, 11:8699-8705

\section{Pre-publication history}

The pre-publication history for this paper can be accessed here: http://www.biomedcentral.com/1471-2407/11/344/prepub

doi:10.1186/1471-2407-11-344

Cite this article as: Min et al: The CpG island methylator phenotype may confer a survival benefit in patients with stage II or III colorectal carcinomas receiving fluoropyrimidine-based adjuvant chemotherapy. BMC Cancer 2011 11:344.

\section{Submit your next manuscript to BioMed Central and take full advantage of:}

- Convenient online submission

- Thorough peer review

- No space constraints or color figure charges

- Immediate publication on acceptance

- Inclusion in PubMed, CAS, Scopus and Google Scholar

- Research which is freely available for redistribution

Submit your manuscript at www.biomedcentral.com/submit
Biomed Central 